\title{
FLIP-FLOPPING: IDEOLOGICAL ADJUSTMENT COSTS IN THE UNITED STATES SENATE
}

\author{
Jason M. DeBacker*
}

January 10, 2014

\begin{abstract}
Using a long panel of roll call voting data, I find that "flip-flopping" senators face significant electoral costs when changing positions. In models of electoral competition, as the costs to candidates changing position approach zero, the equilibrium prediction is the convergence of platforms. Such convergence is at odds with empirical observation. Using a dynamic, structural model of candidate positioning, I identify the nature of the costs associated with changing position that may result in such non-convergence.
\end{abstract}

JEL Classifications: D72; C61

Keywords: Ideology, Voting, Politics

\section{INTRODUCTION}

Models of electoral competition often follow Downs (1957) and allow candidates to freely adjust their positions in the issue space to capture the majority of voters. The result, in a two-candidate election with a single dimensional policy space and single peaked preferences, is both candidates adopting the position of the median voter. Such convergence is rarely observed and is potentially at odds with the party polarization cited by the media and academics (e.g., Poole \& Rosenthal (1991)). A possible source of the non-convergence of positions is candidate reputation (see, for example, Bernhardt \& Ingberman (1985), Enelow \& Munger (1993), and Kartik \& McAfee (2007)). That is, candidates may find it costly to change positions in the issue space because it affects the voter's perceptions of the candidate's credibility or character. Indeed, if media reports can be believed, recent presidential hopefuls John Kerry and Mitt Romney can attest to the electoral costs of

\footnotetext{
* DeBacker: Middle Tennessee State University, Department of Economics and Finance, PO Box 27, Murfreesboro, TN, 37132, jason.debacker@mtsu.edu. Thanks to Rob Williams and Russell Cooper for helpful comments and Tim Groseclose and Sarah Anderson for assistance with the data.
} 
changing positions to attract voters. Despite the large amount of press given to flip-flopping candidates, there have been few empirical tests of the electoral costs candidates face when changing position. ? study voter perceptions of changes in candidate positions and find that voters dislike such changes both because of the uncertainty they introduce into perceptions of future policy positions and because an intrinsic negative reaction to the change. Still no researchers focus on the nature of these costs and the resulting effects on electoral equilibria. For example, do candidates face large fixed costs to changing position that would imply flipflopping is an important behavior?

The following study analyzes the nature of the electoral costs senators face when adjusting their ideological position. Using over 50 years of roll call voting scores from the United States Senate, I estimate the deep parameters of a dynamic, structural model of candidate positioning. The dynamics are important in this context because voter's utility depends upon both current and past positions of candidates, creating a dynamic linkage in the candidates optimization problem. Using a simulated method of moments (SMM) methodology, I identify the nature of ideological adjustment costs in the U.S. Senate. That is, I find the primitive parameters describing the objective functions of voters and candidates by matching moments characterizing the ideological positions of senators and election outcomes to the same moments from model simulations.

Understanding the electoral cost associated with a candidates change in position is important for a number of reasons. First, by finding large costs to adjusting position, one calls into question the empirical validity of the median voter model and the policy predictions based upon it. This is because costs to changing position will pose a barrier to policy convergence in political equilibria. Second, knowing the nature of these costs is important for understanding the role of candidate credibility and reputation in electoral outcomes. For example, if a large part of the costs senators face are fixed costs, we would expect to see more "flip-flopping" senators. That is, senators who hold a position for long periods of time, but who make relatively large changes in position, to move back towards the median voter, when they do make a change. On the other hand, if the costs senators face are increasing with the size of their change in position (e.g., quadratic), we would expect to see more "wishy-washy" senators. These senators would change position more often when 
they deviate from the preferences of the median voter, but with only small moves. Knowing the nature of the costs to changing position is important for predicting electoral equilibria and will shed light on which theoretical models of electoral competition are most appealing on empirical grounds. These size and nature of these electoral costs will tell us whether the cost to flip-flopping is fixed or a function of the distance the candidate moves in the issue space. It will also show whether several small changes or one larger change is the better strategy for a candidate who wishes to change his platform.

The results suggest economically and statistically significant costs of changing position. Further, models that best fit the data are those with both convex and non-convex costs to changing position. That is, the data show senators who are not "flip-floppers" (which would imply a model with only fixed costs), but who change positions slowly. The standard Downsian model, and the median voter models of political equilibrium, are found to be inconsistent with the data on the ideological positioning of U.S. senators. The theoretical models found to be most consistent with the data are those where voters have both uncertainty about the future positions (as in Enelow \& Munger (1993)) of candidates and care about candidate character (as in Kartik \& McAfee (2007)). The implication is that voters penalize any change in position, but that electoral penalties are increasing in the size of the change.

\section{I.I Previous Literature and Motivation}

Models predicting non-convergence of policy platforms in two candidate elections with a single policy dimension come in several flavors. Alesina (1988) presents a model where politicians care about policy in addition to the rents from office and cannot commit to policy platforms. This creates a principal agent problem between the representatives and the voters. While the candidate would like to promise the median voter's preferred position to win the election, such a promise may not be credible and therefore candidate platforms will not converge. A second type of model in which the equilibrium may have non-convergence relies upon uncertainty by the voters about the policy to be implemented when the candidate takes office. The policy in office may differ from the announced policy because of the preferences of the politician (as in Alesina (1988)), because of future events, or because 
the candidate is unsure about his own preferred position. Enelow \& Munger (1993), Bernhardt \& Ingberman (1985), Ingberman (1989), and Banks (1990) all describe models with such uncertainty and derive the equilibrium conditions of electoral competition. Models of Kartik \& McAfee (2007), Callander (2008), and Callander \& Wilkie (2007) adopt a combination of the previous two types of models. Some candidates are policy motivated and others are purely office motivated. However, voters are uncertain about the type of the candidates. Candidates may also have some attribute such as "character" that is valuable to the voters, beyond the policy choice of the candidates. The uncertainty about type of the candidates causes announced positions to become signals of a politicians type, leading to non-convergence of platforms. Most closely related to the present work is the model of candidate flip-flopping between primary and general elections in ?. This model proposes that voters prefer the valence properties of candidates who do not flip-flop (similar to that in Kartik \& McAfee (2007)). The resulting equilibrium is then includes cases where candidates in a general election do not fully converge in their policy platforms.

Each model of non-convergence implies something about the adjustment costs faced by candidates. That is, the about the electoral costs associated with changes in position. For example, Enelow \& Munger (1993) derive the expected utility of the voters when electing a particular candidate and show that the expected utility is decreasing in the size of the change in the candidates' policy platforms. Bernhardt \& Ingberman (1985) and Ingberman (1989) find similar results using slightly different assumptions. The models of Banks (1990), Callander (2008), and Callander \& Wilkie (2007), and Kartik \& McAfee (2007) do not include past position as a state variable, but are only focused on positioning in a oneshot election where candidates may face a personal cost to misrepresenting their position. However, in a dynamic framework, signaling of one's motivation is done both through one's current choice of position, and through the dynamics of one's position. Whether the costs to adjusting position in dynamic versions of these models are convex, as in Enelow \& Munger (1993), or non-convex (as might result from separating equilibria in a signaling game), depends upon the form of the personal costs to candidates for misrepresenting their position. The goal of this study is to empirically identify the form of the electoral costs candidates actually face. 
Empirical models of candidate positioning related to the analysis in the following sections include the work of Glazer \& Robbins (1993), Ansolabehere, Snyder Jr. \& Stewart III (2001), Levitt (1996), Bronars \& Lott Jr. (1997), Poole (2003), and Poole \& Rosenthal (1997). The evidence that politicians make large movements in position due to changes in voter preferences is mixed. Glazer \& Robbins (1993) find the ideological preferences of voters have a substantial effect on the ideological positions of their Representatives. Using the Conservative Coalition interest group's scores to identify the ideological position of Congressman, they find the voters exert much control over the position of their Congressman and deviations from the voters position are small, even for senior congressman. Ansolabehere, Snyder Jr. \& Stewart III (2001) use the National Political Awareness test to identify the positions of both incumbents and challengers in over 100 years of House elections. They find much of a candidate's ideology is explained by his party, and in contrast to Glazer \& Robbins (1993), find little of a candidate's ideological position is determined by local conditions. Levitt (1996) finds senators place the most weight on their own ideological preferences, with the remainder of their ideological stance being approximately equally determined by the preferences of their constituents and their party. However, changes the alignment between voter preferences and senatorial voting records over a senator's career are not explicitly examined by Levitt (1996). Poole (2003) finds little variation in a Congressman's position over his career when using his Nominate scores to define ideological positions. This paper will extend these analyses by further documenting how candidate positions change with changes in the positions of the voters and estimating the impact of these changes on electoral outcomes.

Poole \& Rosenthal (1997) find the vast majority of the variation in roll call voting records can be accounted for by a single dimension, the liberal-conservative spectrum. For example, how one votes on school-vouchers correlates very highly with how one votes on tax reform and welfare programs. Poole \& Rosenthal (1997) have found this single dimension is able to explain the majority of roll call voting patterns, especially after the passage of the Civil Rights Act of 1964 . In fact, they find over $90 \%$ of roll call vote choice can now be explained by the single dimension, liberal-conservative spectrum. These results and the theoretical models described above motivate my use of such a single dimension in the empirical analysis 
done here.

To the best of my knowledge, no empirical work presents an explicit, dynamic model of candidate positioning. The construction of a quantitative, dynamic model of candidate positioning is one of the major contributions of this work. However, the model and estimation used here owes much to work in dynamic economics, such as work by Cooper \& Haltiwanger (2006). Cooper \& Haltiwanger (2006) study the nature of costs to manufacturing plants when adjusting their stock of physical capital. The analysis here draws heavily on their methods and characterization of adjustment costs. One can see a similarity between a plant's choice of physical capital for next period based on current and expected productivity shocks and a candidate's choice of position, which is based on the current and expected positions of the voters. Further, one can see how the nature of adjustment costs shape behavior in a similar manner in both contexts. Fixed costs associated with the investment of physical capital can generate the well-documented patterns of lump investment policies. In the same way, non-convexities in the electoral costs to changes in position can lead to candidates who make large jumps in position (i.e., flip-flop). Thus, many of the modeling and identification tools of dynamic economics can be applied to questions in dynamic political economy.

The remainder of the paper is organized as follows: Section II outlines the theoretical model of candidate positioning in a dynamic environment. Section III describes the data and Section IV discusses the reduced form evidence for a model in which senators face costs to changing position. Section $\mathrm{V}$ presents the econometric methodology and discusses identification. Section VI presents the results and Section VII concludes.

\section{A DYNAMIC MODEL OF CANDIDATE POSITIONING}

The model of candidate positioning, which I describe formally below, has the following basic elements. Voters have single-peaked preferences over policy outcomes in a onedimensional space. Voter's may also penalize candidates for changes in position in this one-dimensional space. These penalties may be because of signals of character derived from 
these changes or because of increases in uncertainty over future positions the candidate will take if elected. Both voters and candidates make decisions with an infinite horizon. Finally, voters derive utility from a time-varying candidate characteristic orthogonal to the candidate's ideology.

Each election features two candidates. As in Downs (1957), candidates only care about the rents from holding office and not policy positions per se. Thus, they choose their positions to maximize the probability of obtaining office. Given the voter's preferences, however, candidates must take into account their past positions when choosing their current platform.

\section{II.I Model of Voters}

Let a voter's preferred position and identity be $\theta$. Candidates and voters have common knowledge of $\theta$, a point in a one dimensional policy space. Call this space "ideology".

Voters select the candidate in the current election who maximizes their expected utility, a function of the policy the candidate puts into place once in office. Further, assume the demographics of the district change over time. That is, the distribution of $\theta$, and in particular the median $\theta, \theta^{m}$, will evolve. Thus $\theta_{t}^{m}$ may not equal $\theta_{t+1}^{m}$. Note, while the distribution of $\theta$ changes, this does not mean each of the voters' preferred points change, only that there are changes in the composition of individuals that make up the senators' constituencies.

Assume the voter's utility is quadratic so the expected utility of $\theta$ voting for candidate $i$, who takes position $x_{i}$ in the one dimensional policy space, is:

$$
E u(i, \theta)=E\left(-\left(x_{i}^{\prime}-\theta\right)^{2}\right)-C\left(x_{i}, x_{i,-1}\right)+\xi_{i},
$$

where a prime denotes a one period ahead variable and the subscript -1 denotes the value from one period prior. The variable $\xi_{i}$ is a random component to the voters' utility, which is distributed i.i.d. and is unobserved by the candidates at the time of their platform choices. This can represent some surge of popularity during the election that is orthogonal to the popularity of the platform and is often called "valence" in the political science literature.

The function $C\left(x_{i}, x_{i,-1}\right)$ is the "cost of adjustment". In a sense, it is a punishment by 
the voters for a candidate's change in position. One may parameterize this function in several ways, according the model of electoral competition one believes to be correct. I discuss the specification of this function and the corresponding models of electoral competition in Section II.IV.

The state variables for the voter's problem are the voter's preferred point, $\theta$, the current positions of the candidates, $x_{i}$, the past positions of the candidates, $x_{i,-1}$, and the transitory shock to the candidates' electoral chances, $\xi_{i}$.

\section{II.II Candidates}

The model period unfolds in the following order. First, the incumbent and challenger simultaneously determine their platforms, $x_{i}$. Challengers are drawn from a population of potential challengers. The candidate's record from the previous period, $x_{i,-1}$ and the current platform choice influences the voters' expectations about the candidates' positions in the

following term, $E\left(x_{i}^{\prime}\right)$, and determine the cost of adjustment associated with any changes in position, $C\left(x_{i}, x_{i,-1}\right)$. After current positions have been determined, the election is held and the winner realized.

Politicians care only about the rents from office and not their policy positions per se. Therefore, they chose a position to maximize the utility of the median voter and thereby maximize the probability of getting elected.

Therefore, candidate $i$, who has tenure $t$, chooses $x_{i}$ to maximize:

$V_{i}\left(x_{i,-1}, t, x_{j}, x_{j,-1}, \theta^{m}\right)=R+\left(1-\delta_{t}\right) \beta P\left(x_{i}, t, x_{i,-1}, x_{j}, x_{j,-1}, \theta^{m}\right) E_{\theta^{m^{\prime}}, x_{j}^{\prime} \mid \theta^{m}} V_{i}\left(x_{i}, t+1, x_{j}^{\prime}, x_{j}, \theta^{m^{\prime}}\right)$

The value of rents, given by $R$, are unimportant other than they must be positive to motivate candidates to run. The continuation value of winning the election is discounted by the probability of winning, $P(\cdot)$, the candidates' rate of time preference, $\beta$, and the probability of retirement, $\delta_{t}$.

Candidates choose a position to maximize the probability of getting elected. The probability of winning is highest if they get as close to possible (bearing in mind the costs of 
adjustment) to the median voter in each period. Without a stochastic term in the instantaneous utility function of the voter, this is $0 / 1$, with the winner completely determined by the past positions of the candidates. Let the optimal decision rule for the candidates' choice of ideological position be given by the function $g\left(x_{i,-1}, t, x_{j}, x_{j,-1}, \theta^{m}\right)$. The model thus unfolds in the following order:

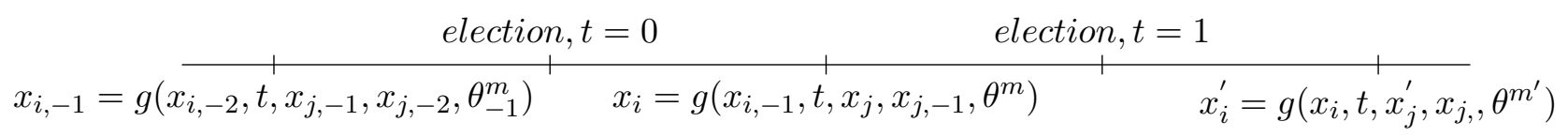

With candidate $i$ choosing position $x_{i}$ given knowledge of the other candidate's current and past positions and the position of the median voter in the election at time $t=1$. The candidates' current and past positions, $x_{i}, x_{j}, x_{i,-1}$, and $x_{j,-1}$ enter into the voter's expected utility function for the election at $t=1$.

\section{II.III Rational Expectations Equilibrium}

Definition 1. A Rational Expectations Recursive Political Equilibrium consists of functions $V\left(x_{i,-1}, t, x_{j}, x_{j,-1}, \theta^{m}\right)$, and $g\left(x_{i,-1}, t, x_{j}, x_{j,-1}, \theta^{m}\right)$ such that for all $i$ :

- Given $x_{i,-1}, t, x_{j}, x_{j,-1}$, and $\theta^{m}, V\left(x_{i,-1}, t, x_{j}, x_{j,-1}\right)$ and $g\left(x_{i,-1}, t, x_{j}, x_{j,-1}, \theta^{m}\right)$ solve the candidate's problem.

- Given $g\left(x_{i,-1}, t, x_{j}, x_{j,-1}, \theta^{m}\right)$, the voters choose the candidate who maximizes their expected utility.

- Voter's have rational expectations: $E\left(x_{i}^{\prime}\right)=\int_{\theta^{m^{\prime}}} \int_{x_{j}^{\prime}} g\left(x_{i}, x_{j}^{\prime}, x_{j}, \theta^{m^{\prime}}\right) d x_{j}^{\prime} d \theta^{m^{\prime}}$

The above are standard conditions for the equilibrium of a repeated, two candidate electoral game. The value functions and policy functions are such that they solve the candidates' problems. The voters select the candidate that maximizes their utility and hold beliefs about the candidates' policy functions that are consistent with the actions of these candidates. 


\section{II.IV Ideological Adjustment Costs}

The adjustment costs function that politicians face is represented by a penalty function in the voter's utility. The shape of this reduced form function depends upon the theoretical model of voter preferences and electoral competition assumed. I outline three general cases below, relating each to the relevant political economy models and discussing their implications for the behavior of candidates.

\section{II.IV.1 Zero Costs of Adjustment}

If changing position has no effect on a candidate's electoral prospects, then we are in the stylized Downsian world. In this case, the costs of to any candidate $i$ of moving from position $x_{i,-1}$ in the prior period to $x_{i}$ in the current period is given by $C\left(x_{i}, x_{i,-1}\right)=0$. Under this parametrization, candidates will always align themselves with the current position of the median voter, regardless of their past position.

\section{II.IV.2 Convex Costs of Adjustment}

Bernhardt \& Ingberman (1985), Ingberman (1989), and Enelow \& Munger (1993) derive equilibria of electoral competition when voters are uncertain about the policies of candidates. The voters may be unsure the candidate will deliver on their campaign promises for a number of reasons. Writing the expected utility of voting for candidate $i$ :

$$
E u(i, \theta)=E\left(-\left(x_{i}^{\prime}-\theta\right)^{2}\right)+\xi_{i}
$$

One can pass through the expectations operator, perform some algebraic manipulation and find:

$$
\left.E u(i, \theta)=-\left(E\left(x_{i}^{\prime}\right)-\theta\right)^{2}\right)-\sigma_{x_{i}}^{2}+\xi_{i},
$$

where, costs to changing position result from increasing uncertainty regarding future positions. These costs are given by $\sigma_{x_{i}}^{2}$, the variance in the expected future positions of candidates. Given risk averse voters, as uncertainty about the future policies of the can- 
didates increases, expected utility decreases. It is natural for voters to use the past record of candidates when updating their expectations about the candidate. In Enelow \& Munger (1993), a change in position by the the politician increases the uncertainty of the voters and does so in a quadratic manner. Uncertainty increases at a rate proportional to the squared difference between the politicians past and current positions. This result is captured in the following specification of adjustment costs:

$$
\sigma_{x}^{2}=C\left(x_{i}, x_{i,-1}\right)=\frac{\gamma}{2}\left(x_{i}-x_{i,-1}\right)^{2}
$$

Facing the convex adjustment costs of Equation II.5, senators will not be especially responsive to changes in the preferences of their constituents. While candidates will want to align themselves with the voters, the costs of changing position increase quickly as one makes larger moves. Such costs force senators to change position only in small increments. Senators will be "wishy-washy", making slight moves in any direction as the voters' preferred points in the ideological space change, but rarely making large jumps in their ideological position.

In addition to the quadratic case, I also consider a model where the costs of adjustment are linear. Such costs are consistent with the models of Bernhardt \& Ingberman (1985) and Ingberman (1989), who allow the uncertainty of voters to be any function that is increasing the size of the deviations of candidates from their past record. These costs take the following form:

$$
\sigma_{x}^{2}=C\left(x_{i}, x_{i,-1}\right)=\kappa\left(\left|x_{i}-x_{i,-1}\right|\right)
$$

\section{II.IV.3 Non-convex Costs of Adjustment}

Still other models of candidate positioning assume the costs of adjusting one's position are related to the signaling of character. That is, voters derive utility from both the ideological stance of the politician and from the "character" of the politician. Kartik \& McAfee (2007) and Callander \& Wilkie (2007) describe models with just such a mechanism. In a dynamic version of these models, there may be a non-linear relationship between the size of 
one's change in position and the penalty on pays for the change. If one either has character or does not (as in Kartik \& McAfee (2007)), holding one's ground signals good character and any change in position signals one has no character. In a separating equilibrium, no character types will reveal themselves by changing position. Since character is valuable, these candidates will face a lower probability of election than candidates who have the same platform, but signal having character. I model the dynamic signaling of character with a fixed cost to adjusting position. The adjustment cost function for candidate $i$ is thus:

$$
C^{N C}\left(x_{i}, x_{i,-1}\right)=0
$$

where $C^{N C}$ is the cost function when one does not change position $\left(x_{i}=x_{i,-1}\right)$. And:

$$
C^{C}\left(x_{i}, x_{i,-1}\right)=F
$$

where $C^{C}$ is the cost function when one changes position and $F$ is the fixed cost to changing position. Call the associated probabilities of re-election $P^{N C}\left(x_{i,-1}, x_{j}, x_{j,-1}, \theta^{m}\right)$ and $P^{C}\left(x_{i}, x_{i,-1}, x_{j}, x_{j,-1}, \theta^{m}\right)$, respectively. On can thus write the dynamic programming problem of the senator as:

$$
V\left(x_{i,-1}, t, x_{j}, x_{j,-1}, \theta^{m}\right)=\max \left[V^{N C}\left(x_{i,-1}, t, x_{j}, x_{j,-1}, \theta^{m}\right), V^{C}\left(x_{i,-1}, t, x_{j}, x_{j,-1}, \theta^{m}\right)\right]
$$

Where

$$
V^{N C}\left(x_{i,-1}, t, x_{j}, x_{j,-1}, \theta^{m}\right)=R+(1-\delta) \beta P^{N C}\left(x_{i,-1}, x_{j}, x_{j,-1}, \theta^{m}\right) E_{\theta^{m}, x_{j}^{\prime}} V\left(x_{i}, t+1, x_{j}^{\prime}, x_{j}, \theta^{m^{\prime}}\right)
$$


and

$V^{C}\left(x_{i,-1}, t, x_{j}, x_{j,-1}, \theta^{m}\right)=R+(1-\delta) \beta P^{C}\left(x_{i}, x_{i,-1}, x_{j}, x_{j,-1}, \theta^{m}\right) E_{\theta^{m}, x_{j}^{\prime}} V\left(x_{i}, t+1, x_{j}^{\prime}, x_{j}, \theta^{m^{\prime}}\right)$

Candidates facing fixed costs to changing position will change positions only when they are further away from the voters than a certain threshold, as determined by $F$. Senators facing fixed costs to adjustment will hold positions for a long period of time, but make larger changes than those in the convex models when they do change. In other words, these candidates flip-flop.

\section{DATA}

Estimation of the model of candidate positioning requires data on the ideological positions of senators and their constituents, observations of senators' retirement decisions, and data on election outcomes. The data on Senate retirements and election outcomes is straight forward to collect. These data come from Stewart III \& Woon (2006) (retirements), the ICPSR Congressional Biography Data Series (retirements), and the Federal Election Commission (election results) and I omit a detailed discussion of these data sources. The data on ideology requires a more thorough description.

Data on the ideological position of senators and voters come from the Americans for Democratic Action (ADA) interest group ratings of roll call votes. Each year, the ADA select a subset (20 votes) of the year's roll call votes and rate each Congressman on a scale of 0 to 100. A score of 0 means the Congressman voted against the ADA's position on every roll call vote and 100 means the Congressman voted for the ADA's position on every roll call vote. Thus a score of 0 indicates the the Congressman is very conservative and a score of 100 indicates the Congressman is very liberal, as defined by the ADA. The sample period is $1947-20061^{1}$

Adjustments are made to these scores to allow them to be comparable across time

\footnotetext{
${ }^{1}$ Data from 1947-1959, 1962, and 1964 are constructed by Tim Groseclose based on the ADA's methodology and list of key votes for 1947-1959. The ADA did not publish scores for this time period.
} 
and chambers. These adjustments are described in Groseclose, Levitt \& Snyder (1999). Such adjustments to the raw ADA scores are necessary because the issues voted on vary over time and across chambers and so the raw scores are not directly comparable. The adjustments are used to allow the ADA scores to shift and stretch across time and chambers. Thus converting raw scores to adjusted scores is similar to converting temperature from Fahrenheit to Celsius. The adjusted scores are not bounded between 0 and 100. Table 1 presents summary statistics for the adjusted and nominal ADA scores, separating out the scores for each major party. These data are available for the entire 1947-2007 period from Anderson \& Habel (2008).

Table 1: ADA Scores

\begin{tabular}{lcc}
\hline \hline Variable & Mean & Std. Dev \\
\hline Adjusted ADA Score & 37.774 & 31.605 \\
Democrats, Adjusted ADA Score & 56.535 & 26.337 \\
Republican, Adjusted ADA Score & 15.463 & 21.108 \\
Nominal ADA Score & 46.238 & 34.458 \\
Democrats, Nominal ADA Score & 67.011 & 28.446 \\
Republicans, Nominal ADA Score & 21.535 & 22.666 \\
\hline
\end{tabular}

There are several advantages to ADA scores over other measures of ideology, such as the Nominate scores of Keith Poole and Howard Rosenthal. First, ADA scores have a clear definition (i.e. position on the liberal-conservative spectrum, as defined by the ADA). Second, due to the work of Groseclose, Levitt \& Snyder (1999), they are comparable over time and across chambers $2^{2}$ Third, they are reported at a higher frequency $\mathrm{L}^{3}$

The mean of the ADA scores of the state's House delegation are used as a proxy for the ideological position of each state's voters. This follows the work of Levitt (1996), who uses the same proxy for the preferences of each state's voters 4 If House members face adjustment costs similar to those faced by Senator's then this proxy variable will bias the estimates of the adjustment costs faced by Senators. The result will be a downward bias on the size of the adjustment costs estimated. The reasoning is as follows. If House members face positive adjustment costs, then their positions (and thus my proxy for voter preferences) will move less than one point for each one point change in the preferences of the median

\footnotetext{
${ }^{2}$ D-Nominate scores are comparable over time, but not across chambers. They are also constructed in such a way as to constrain the ideological position of a Congressman to change in a linear fashion.

${ }^{3}$ ADA scores are reported annually, whereas Nominate scores are reported only for each Congress.

${ }^{4}$ The median ideological position of the House delegation gives similar results.
} 
voters. Senators will respond to the true voter preferences. Thus by using the positions of House members as a proxy for voter preferences, it will look as those Senators move closer to the positions of voters than they in fact do. Since the model is in part identified through the assumption that adjustment costs are the frictions preventing Senators from moving close to the positions of the median voter, the result will be downward biased adjustment cost parameter estimates.

Because the ADA scores are based on such a small number of votes, there may be much year to year variation due to the votes the ADA considers each year. To mitigate this noise, I define a model period as a term in the senate and average the scores across the period. I do not calculate scores for senators who did not receive a score in two or more years of the six year term, ensuring the ideological position of each senator is based on at least 80 votes. This leaves me with 960 senator-term observations over the sample period of 1947-2006. Included in this sample are 400 different senators. Of these 137 serve only one term, 104 serve two terms, 77 serve three terms, 48 serve four terms, and 34 serve five or more terms during the sample period. From the sample, I am able to observe 557 potential changes in position.

Table 2: Summary Statistics

\begin{tabular}{lr}
\hline \hline Variable & \\
\hline Mean years observe Senator & 10.387 \\
Mean size of change & 0.219 \\
Mean of abs value of change & 6.215 \\
Serial correlation of changes & -0.098 \\
Serial correlation of abs value of changes & 0.263 \\
Correlation of changes in voter and senator & 0.056 \\
Correlation of voter ideology and senator ideology & 0.551 \\
Fraction of jumps ( $\geq 20$ point change) & 0.025 \\
\hline \hline
\end{tabular}

Summary statistics for the ADA data are presented in Table 2. Figure 1 displays a histogram of the distribution of ideological changes, $\left(x-x_{-1}\right)$ and shows a distribution with a mass toward zero. This figure is important for thinking about whether those costs are convex or non-convex. Convex costs would suggest most movements would be small and there would be a positive correlation between the movements. Indeed, the mass towards zero supports this. Over $11 \%$ of the changes are less than one point on the ADA scale and over $20 \%$ are less than 2 points on the scale. Non-convex costs would suggest a long right 


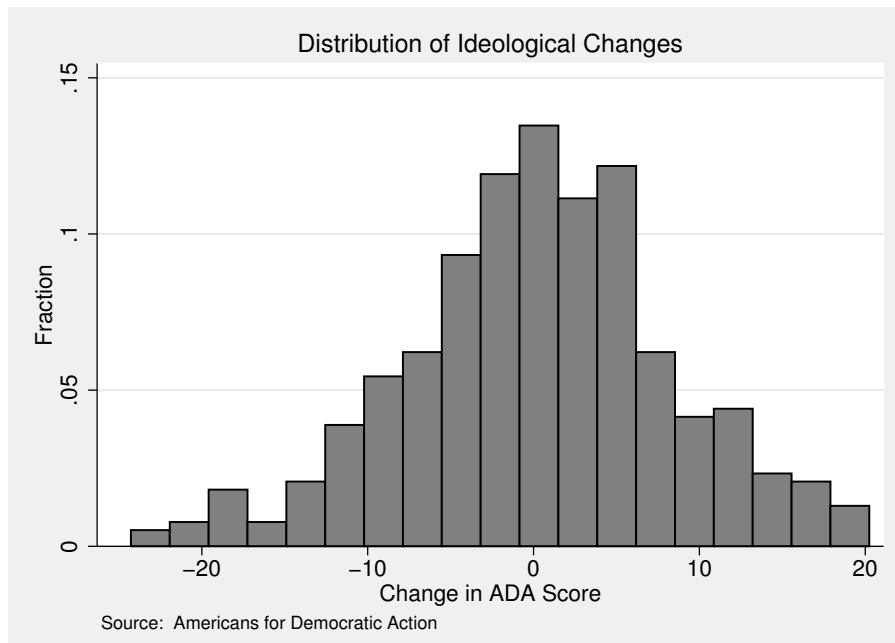

Figure 1: Distribution of Changes in Position by Senators

tail (i.e. many senators making big jumps), which is not evident from Figure 1. Of all changes in position, the moves larger than 20 points on the ADA scale account for about $7 \%$ of the total change in position. These "jumps" constitute $2.5 \%$ of the observations.

If costs were zero, then one would expect a high correlation between changes in voter ideology and changes in senator ideology and also a high correlation between the observed ideology of senators and voters. The correlation of changes in Table 2 is low, at 0.06 and the correlation of observed ideologies is 0.551 . With zero cost of adjusting position both of these correlations would be 1.00 .

\section{EVIDENCE OF IDEOLOGICAL ADJUSTMENT COSTS}

\section{IV.I Non-parametric Evidence}

The distance between the position of the senators and the voters as measured by the ADA scores certainly has an effect on electoral outcomes. As a measure of electoral outcomes, I employ the candidate's share of the two party vote. Note that the theoretical model predicts that, on average, the candidates who position themselves closer to the median voter will fare better, but not necessarily win the election, given the stochastic valence term. The unconditional correlation between a senators' share of the two-party vote and his distance 
from the voters is -0.25 and is plotted in Figure 2. This relationship is strong and negative, as one might expect.

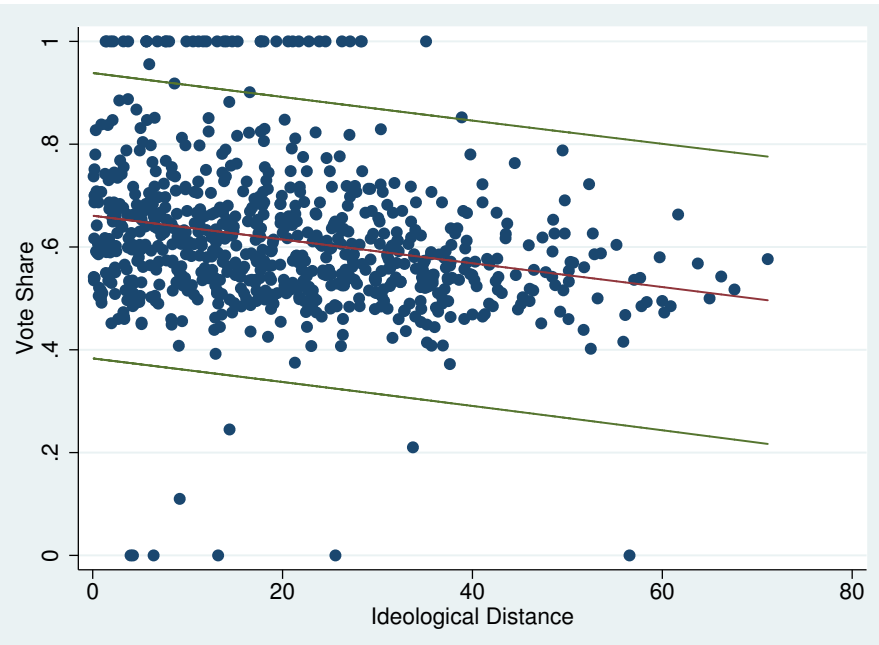

Figure 2: Correlation of Ideological Distance and Vote Share

Changing position also negatively effects one's electoral prospects. The unconditional correlation between the candidate's share of the two party vote and the absolute value of his change in position is -0.08 (Figure 3). While not as strong as the relationship between distance and vote share, changes in position suggest a lower chance of electoral success.

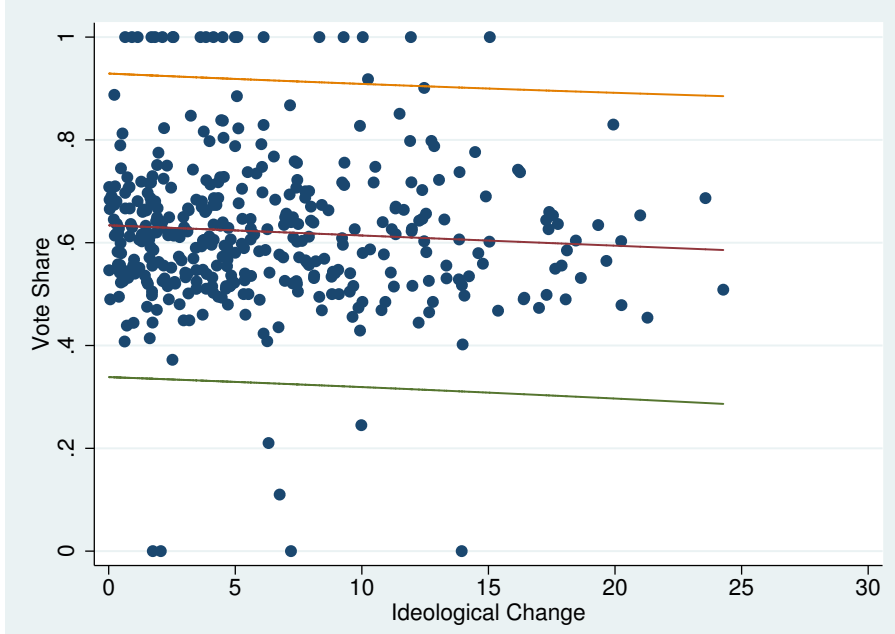

Figure 3: Correlation of Ideological Change and Vote Share 


\section{IV.II Least-squares Evidence}

One might worry the unconditional correlation between vote share and the size of a candidate's change in position is biased downward because those who change in position are likely to be those whose ideological position is far from the voters' preferred point. To correct for this, I regress the candidate's share of the two party vote on ideological distance, changes in ideology, and changes in state economic conditions, candidate seniority, and national and state trends in party popularity. Tufte (1975) and Erikson (1990) find support for the role of economic conditions in the outcomes of Congressional elections and prompt me to control for changes in state income. Alesina \& Rosenthal (1989) find controlling for national sways in opinion are important, therefore I include fixed effects for the interaction of the candidate's party and the year of the election. I also include fixed effects for partystate interactions, as a Democrat who is elected in a Republican state may face stronger opposition in elections than a Republican, even if the measured ideology is the same.

Table 3: Effects of Changes in Ideology on Incumbent Vote Share

\begin{tabular}{|c|c|c|c|c|c|c|}
\hline $\begin{array}{l}\text { Dependent Variable: } \\
\text { Variable: }\end{array}$ & $\begin{array}{c}\text { Candidate's Share } \\
1\end{array}$ & $\begin{array}{c}\text { of Two Party Vote } \\
2\end{array}$ & 3 & 4 & 5 & 6 \\
\hline Ideological Distance & $\begin{array}{c}-0.004^{* * *} \\
(0.001)\end{array}$ & $\begin{array}{c}-0.004^{* * *} \\
(0.001)\end{array}$ & $\begin{array}{c}-0.004^{* * *} \\
(0.001)\end{array}$ & $\begin{array}{l}-0.001 \\
(0.001)\end{array}$ & $\begin{array}{l}-0.001 \\
(0.001)\end{array}$ & $\begin{array}{l}-0.001 \\
(0.001)\end{array}$ \\
\hline Abs(Change in Ideology) & $\begin{array}{l}-0.165 \\
(0.129)\end{array}$ & & $\begin{array}{l}-0.064 \\
(0.384)\end{array}$ & $\begin{array}{l}-0.09 \\
(0.15)\end{array}$ & & $\begin{array}{c}0.105 \\
(0.409)\end{array}$ \\
\hline Square of Change in Ideology & & $\begin{array}{l}-0.009 \\
(0.006)\end{array}$ & $\begin{array}{l}-0.006 \\
(0.019)\end{array}$ & & $\begin{array}{c}-0.006 \\
(0.008)\end{array}$ & $\begin{array}{c}-0.011 \\
(0.022)\end{array}$ \\
\hline Seniority & $\begin{array}{l}1.845^{* *} \\
(0.591)\end{array}$ & $\begin{array}{l}1.855^{* *} \\
(0.593)\end{array}$ & $\begin{array}{l}1.852^{* *} \\
(0.592)\end{array}$ & $\begin{array}{l}0.243 \\
(0.63)\end{array}$ & $\begin{array}{c}0.255 \\
(0.632)\end{array}$ & $\begin{array}{c}0.255 \\
(0.633)\end{array}$ \\
\hline$\%$ Change in State Income & $\begin{array}{l}14.036 \\
(9.936)\end{array}$ & $\begin{array}{l}13.975 \\
(9.939)\end{array}$ & $\begin{array}{l}14.011 \\
(9.944)\end{array}$ & $\begin{array}{c}7.604 \\
(10.406)\end{array}$ & $\begin{array}{c}7.477 \\
(10.375)\end{array}$ & $\begin{array}{c}7.431 \\
(10.392)\end{array}$ \\
\hline Year*Party Effects & Yes & Yes & Yes & Yes & Yes & Yes \\
\hline State*Party Effects & No & No & No & Yes & Yes & Yes \\
\hline Obs & 366 & 366 & 366 & 366 & 366 & 366 \\
\hline$R^{2}$ & 0.967 & 0.967 & 0.967 & 0.974 & 0.974 & 0.974 \\
\hline
\end{tabular}

a $* p<0.05,{ }^{* *} p<0.01,{ }^{* * *} p<0.001$

b Standard errors in parentheses below parameter estimates.

Table 3 reports the results of these regressions. Ideological distance is defined as the square of the distance between the voters and the senator, $(\theta-x)^{2}$. Changes in ideology are measured in two ways. First, by the absolute value of the change, $\left|x_{i}-x_{i,-1}\right|$. Second, by the square of the change in position, $\left(x_{i}-x_{i,-1}\right)^{2}$. The coefficients on distance from 
the voters and changes in positions have the expected (negative) sign in all specifications. Changes in state income are positively related to a candidate's electoral prospects, which is anticipated, as all candidates included in the regressions are incumbents. In fact, they are all incumbents with at least two terms of tenure, which is needed to calculate changes in position. The effect of seniority is not consistent across models, but after the "sophomore surge", the literature finds small returns to being an incumbent 5

While the coefficients on a change in ideology are not statistically significant, the signs consistent with the theoretical model - changes in position negatively affect one's vote share in any model. A 10 point change in ideology results in a decrease of between 0.9 and 1.7 percent of the vote share, which is non-trivial. In fact, in model (1), a change in position of 6.22 ADA points (the average size of a change in position) is equivalent to a candidate being $16 \mathrm{ADA}$ points further away from the voters. To put this in perspective, the difference between the positions of Senators John McCain and Strom Thurmond, moderate and very conservative senators, respectively, is less than nine points on the ADA scale.

There is a potential for a downward bias on the coefficients on ideological distance and changes in position. This bias comes from two sources. First, if running in an election is costly, those who run are likely to be those who anticipate winning. Thus, those with a past voting record closer to the ideal position of the voters and who do not have to make large changes in position will run for office, while those who are far from the voters and would have to make large changes do not run. Not controlling for the endogeneity of candidates biases the estimated relationship between changing position and electoral success towards zero. Second, among those who run, those changing position are going to be those who are more likely to lose the election; those with a voting record far from the voters and who face a strong candidate. Evidence of such behavior can be found in Somer-Topcu (2009), who documents parties changing position in response to weak election outcomes. The effect of failing to account for the endogenous relationship between changes in position and vote share results in a downward bias of the estimated relationship between the two variables. In order to account for these possible sources of bias, I estimate Heckman selection models where I instrument for the decision to run using the candidate's seniority and models in

\footnotetext{
${ }^{5}$ See, Gowrisankaran, Mitchell \& Moro (2008), for example.
} 
which I instrument for changes in position with the change in position of the voters. Both models give larger point estimates of the coefficients on changes in position, but the standard errors are very large.

Another way to control for selection and the endogeneity of changes in position is to estimate a model of candidate positioning in a more direct fashion. This has the further advantage of controlling for the position of challengers. By not controlling for the position of challengers, I am biasing the estimates of the effects of changing position. For example, imagine a case where the challenger takes a position very near the median voter and has a record that is close to the median as well. In such a case, the incumbent will likely have to move close to the median also, but he will face a low probability of winning given the proximity of the challenger to the position of the median voter. In this case, large changes in position come in cases when the incumbent has a relatively low probability of victory. Thus the estimates of the electoral costs to changing position are biased upward. Estimating a structural model allows me to control for these sources of endogeneity by explicitly including them in the optimization problems of the agents. That is, when the model is simulated these endogenous relationships are a part of the simulated behavior, allowing for unbiased estimates of the deep parameters of the model. In the next section, I discuss the structural estimation of a model of candidate positioning when changing position is costly.

\section{STRUCTURAL ESTIMATION}

\section{V.I Estimable Model}

In order to estimate the dynamic model described in Section II , one needs data on the past records of both candidates, the current positions taken by both candidates, and the preferred position of the median voter. I use ADA scores to proxy for the current and past positions of those who have served in the Senate. A candidate's voting record during his term in office serves as his platform for the election at the end of that term. No available data allow me to observe the past positions of first term senators or the past or the current

position taken by those who have never served in the Senate. Because of this limitation, I 
assume a distribution for the positions of challengers and the costs of adjustment associated with these positions. The model of challengers is reduced form, but consistent with both an incumbency advantage (as in Bernhardt \& Ingberman (1985)) and with the model of candidate positioning described above. This simplification captures much of the richness of the model from Section II, while allowing one to estimate the underlying parameters of the model in the absence of data on challenger positions.

Specifically, the challenger's current position, $x_{C}$, and the costs associated with this position, $C_{C}$, are drawn from a bivariate normal distribution with mean $\mu$ and covariance $\Sigma_{C}$. These assumptions imply the expected utility of electing a challenger is:

$$
E u(C, \theta)=-\left(E\left(x_{C}^{\prime}\right)-\theta^{m}\right)^{2}-C_{C}+\xi_{C}
$$

The function $E\left(x_{C}^{\prime}\right)$ is a function of the current position of the challenger, $x_{C}$, which the econometrician cannot observe since there is no available voting record for the challenger. Therefore, I model the challenger's current position as a random draw with $x_{C} \sim$ $N\left(\mu_{x_{C}}, \sigma_{x_{C}}\right)$. In addition, because I do not want to assume challengers and incumbents face the same costs to changing position, the costs of adjustment, $C_{C}$, associated with the challenger and his position are also stochastic; $C_{C} \sim N\left(\mu_{C}, \sigma_{C}\right){ }^{6}$ Allowing for a correlation between one's current position and the costs of changing position is natural, as one might expect there to be more uncertainty if a candidate adopts a more centrist position because he may be playing to the voters (see Enelow \& Hinich (1981), Kartik \& McAfee (2007)). Let $\rho_{C, x_{C}}$ be the correlation between the challenger's current position and the costs associated with that position.

Alternatively, one could assume the challengers' cost of adjustment function. Knowing the form of this cost of adjustment function, one need only draw the past position of the challenger. Given the cost function and the position of the incumbent, the challenger's equilibrium decision rule will omit his optimal ideological position. However, one is not able to identify both the parameters of the cost function for challengers and the distribution of their past positions. Thus, I assume a parametrization of the stochastic processes summa-

\footnotetext{
${ }^{6}$ The incumbency advantage can thus be built into this general cost parameter.
} 
rizing the best response function of the challengers and their costs of adjusting position. These can be summarized through the draw of their current position and the challenger cost function, which represents the cost to moving to their current position (a function of their current and past positions, neither of which are observable in the data).

Assuming $\xi_{i}$ is distributed i.i.d., Type 1 Extreme Value and is additively separable in the utility function, one can write the politicians expected probability of victory as:

$$
P\left(i \text { wins } \mid x_{i}, x_{i,-1}, x_{j}, x_{j,-1}, \theta^{m}\right)=\frac{\exp \left(E u_{i}\left(x_{i}, x_{i,-1}, \theta^{m}\right)\right.}{\sum_{i=1}^{2} \exp \left(E u_{i}\left(x_{i}, x_{i,-1}, \theta^{m}\right)\right)}
$$

Thus, the probability the incumbent wins is:

$$
P\left(I \text { wins } \mid x_{I}, x_{I,-1}, x_{C}, C_{C}, \theta^{m}\right)=\frac{\exp \left(E u_{I}\left(x_{I}, x_{I,-1}, \theta^{m}\right)\right.}{\exp \left(E u_{I}\left(x_{I}, x_{I,-1}, \theta^{m}\right)\right)+\exp \left(E u_{C}\left(x_{C}, C_{C}, \theta^{m}\right)\right)}
$$

Following Enelow \& Munger (1993), voter expectations about future candidate positions take a specific functional form, although in this case voter expectations are assumed to be forward-looking. These expectations take the following form: $E\left(x_{i}^{\prime}\right)=\lambda x_{i}+(1-\lambda) E \theta^{m^{\prime}}$. In the results which follow, I fix $\lambda$ at 0.5 . Positing a functional form for voter expectations of future candidate positions helps to pin down the voters' beliefs.

The utility and expectations of voters, the stochastic valence of candidates, the motivation of candidates, and the exogenous processes describing challengers put structure on the model. The parameters of this model are estimated using data on the positions taken by senators on the liberal-conservative spectrum defined by the ADA. The expected value of a candidate's policy next period is determined by expectations about the evolution of the median voter and decision rules of the candidates.

\section{V.II Estimating Voter Preferences and Non-electoral Exit Probabilities}

The decisions of the senators depend importantly upon retirement probabilities and the expectations of the future positions of voters. Retirement probabilities depend upon the tenure of the senator and help to define how future elections are discounted. On average, 
just under $10 \%$ of senators retire each term. The probability of retirement, $\delta_{t}$, is found by calculating the empirical probability that a senator with a given level of tenure retires. That is, retirement decisions are not modeled as strategic choices, as in ?. The assumption of exogenous probabilities of non-electoral exit is consistent with the evidence of Ansolabehere \& Snyder (2004) who find no evidence that candidates for statewide office retire strategically. Gowrisankaran, Mitchell \& Moro (2008) also propose that senator's retirement probabilities are non-strategic. 7

\section{Table 4: Parameters}

\begin{tabular}{lrl}
\hline \hline Parameter & Value & Source \\
\hline$\beta$ & 0.960 & $4 \%$ Risk free rate \\
$\delta_{t}$ & $0.08-0.35$ & Empirical prob retire \\
$\rho$ & 0.533 & Estimated persistence of median voter position \\
$\sigma_{\epsilon}$ & 12.935 & Estimated std dev of shock to median position \\
\hline
\end{tabular}

Understanding the persistence and variability in the preferences of the voters are key components to the solution of the senators' dynamic programming problem. The bliss point of the decisive voter is unaffected by the positions of the senators and is assumed to follow and $\operatorname{AR}(1)$ process:

$$
\theta_{t}^{m}=(1-\rho) \mu+\rho \theta_{t-1}^{m}+\epsilon_{t}
$$

I assume $\epsilon \sim N\left(0, \sigma_{\epsilon}\right)$ and use the mean ADA score of the House delegation from the senator's state as a proxy for the preferences of the decisive voter, as done in Levitt (1996). The $\operatorname{AR}(1)$ process is estimated using a least squares approach where the mean of the autoregressive process is allowed to vary across states. I assume both $\rho$ and $\sigma_{\epsilon}$ are constant across states and find them to be 0.44 and 11.50 , respectively. The AR(1) process is then approximated by a first-order Markov process following the method of Tauchen (1986) to determine the transitions of the voters in the discretized state space of the computational model. Because the preferences of voters are exogenous to the choice of position by senators, it is not necessary to estimate the distribution of voter preferences within the structural model.

\footnotetext{
${ }^{7}$ Note that the probability of winning is not a function of tenure, while retirement is. The evidence supports these assumptions. Dawes \& Bacot (1998) and DeBacker (2011) find that the incumbency advantage is flat over tenure. Gowrisankaran, Mitchell \& Moro (2008) even find evidence that tenure is disadvantageous in U.S. Senate election outcomes.
} 
In addition to the exit probabilities and the law of motion for the median voter, I also set the values of several model parameters before the structural estimation stage. As noted by Rust (1987), it is difficult to estimate the rate of time preference in discrete choice dynamic programming problems. Therefore, I set the value of $\beta$ to an annual value of 0.96 , consistent with a $4 \%$ risk free interest rate. The decision rules of senators depend upon the differences in ideology between the candidates and the median voter. Therefore, I assume the mean of the distribution of challenger ideology, $\mu_{x_{C}}$, is the same as the mean from the distribution of the median voters' preferred points. For the following analysis, I also assume the correlation between the ideology of challengers and the adjustment costs of challengers, $\rho_{C, x_{C}}$, is zero 8

\section{V.III Estimating Ideological Adjustment Costs}

Using an indirect inference method, I estimate the following model parameters: $\mu_{C}, \sigma_{C}, \sigma_{x_{C}}$, and the parameters describing the costs of adjustment function $C\left(x_{i}, x_{i,-1}\right)$. These remaining parameters underlying the model of candidate positioning, $\Theta=\left(\mu_{C}, \sigma_{C}, \sigma_{x_{C}}, \gamma, \kappa, F\right)$, are identified through a simulated method of moments (SMM) estimation procedure as described in McFadden (1989). The SMM methodology has several advantages over alternative methods of estimation such as maximum likelihood. First, SMM is transparent. The moments I choose to match are well measured, clearly defined, and easily interpreted. Second, given the non-convex costs of adjustment, if one were to use MLE, the data would have to be measured very precisely in order to identify a "no change" in position. The data used here do not satisfy such a strict requirement.

The SMM procedure has the following algorithm. For a given vector of parameters, $\Theta$, the dynamic programming problem (DPP) of the senator is solved. The solution to the DPP is a set of policy functions determining the senator's optimal choice of ideological position given his past position, the position of the challenger, the adjustment cost associated with the challenger's position, the current position of the voters, and the electoral shock $\xi$. These

\footnotetext{
${ }^{8}$ Without data on the positions of challengers, it is not possible to estimate this correlation. As a robustness check of the results, I estimate the model under alternative assumptions for the correlation between the distance between the position of the challenger and the median voter and the adjustment costs those challengers face. Changes to this assumption have very little impact on the fit of the model and result in no change to the model which best fits the data (a model with fixed and quadratic costs).
} 
policy functions are used to simulate a panel of policy choices and electoral outcomes . A set of moments is calculated from the simulated panel. Call the vector of simulated moments $\Psi^{s}(\Theta)$.

The estimate $\hat{\Theta}$ is the vector of parameters that minimizes the weighted distance between $\Psi^{s}(\Theta)$ and the vector of moments from the data, $\Psi^{d}$. Formally, $\hat{\Theta}$ solves:

$$
£(\Theta)=\min _{\Theta}\left[\Psi^{d}-\Psi^{s}(\Theta)\right]^{\prime} W\left[\Psi^{d}-\Psi^{s}(\Theta)\right]
$$

where $W$ is the optimal weighting matrix, calculated as the inverse of the variance covariance matrix of the data moments, as described in Gourieroux, Monfort \& Renault (1993). This weighting matrix is calculated by bootstrapping the data. Using the SMM procedure with the optimal weighting matrix ensures consistent and efficient estimates of $\Theta$.

In the minimization routine, the vector $\Theta$ is updated using a simulated annealing algorithm (Goffe, Ferrier \& Rogers (1994)). Such an algorithm is very effective at finding the global minimum in cases where the objective function is non-linear in its parameters, as in this case.

\section{V.IV Moments and Identification}

To estimate $\Theta$, I choose to match the following moments: the fraction of jumps in position (a change in position of at least 20 points on the ADA scale), the serial correlation of changes in position, the re-election rate of incumbents, the correlation between re-election rates and the distance between a senator and voter's position, the correlation between the ideology of senators and voters, the correlation between the ideology of senators and voters for first term senators, and the standard deviation of positions for first term senators $!^{9}$ Table 5 summarizes the moments. While each of the moment is affected by all the parameters to some extent, I discuss next which moments contribute most to the identification of each parameter.

The fraction of jumps and the serial correlation in changes of position are most informative about the size and nature of the costs of adjustment. In the quadratic adjustment

\footnotetext{
${ }^{9}$ Changing the value that defines a jump has little effect on the parameter estimates. A higher (lower) value for the definition only decreases (increases) the moment that is the fraction of jumps.
} 


\section{Table 5: Moments Used For Estimation}

\begin{tabular}{lc}
\hline \hline Moment & \\
\hline Fraction of Jumps ( $\geq 20$ point change) & 0.025 \\
Serial Corr of Changes & 0.263 \\
Incumbent Re-election Rate & 0.843 \\
Correlation(win,distance) & -0.119 \\
Correlation of voter and senator ideology & 0.551 \\
Correlation of voter and 1st term senator ideology & 0.462 \\
Freshman Re-election Rate & 0.829 \\
\hline \hline
\end{tabular}

\section{Table 6: Parameters}

\begin{tabular}{ll}
\hline \hline Parameter & Definition \\
\hline$\mu_{C}$ & Mean of challenger adjustment costs \\
$\sigma_{C}$ & Std. dev. of challenger adjustment costs \\
$\sigma_{x_{C}}$ & Std. dev. of challenger position \\
$\kappa$ & Coefficient in linear costs of changing position \\
$\gamma$ & Coefficient in quadratic costs of changing position \\
$F$ & Fixed cost of changing position \\
\hline
\end{tabular}

costs model, a larger value of $\gamma$ implies fewer jumps. The fixed-cost model has more jumps than the quadratic model, and the number of jumps increases as $F$ decreases (for certain ranges of $F$ ).

The serial correlation is also informative about the nature of the costs of adjustment. With quadratic costs of adjustment, one will find a relatively high degree of serial correlation. This is because senators will not make large changes in position because the costs to changing position are increasing with the size of the change. With linear costs of adjustment, the marginal cost of a change in position does not depend upon the size of the change, so the changes will be larger and the serial correlation lower. When costs are independent of the size of one change, as in the fixed cost case, the serial correlation will be lowest. Facing fixed costs of adjustment, candidates will only change position when they are beyond a certain threshold from the voters and will make large changes in position in one term, with little activity at other times.

Re-election rates are determined by a number of the parameters, but they most directly help to pin down the mean adjustment costs faced by challengers, $\mu_{C}$. Higher adjustment costs for challengers leads to a larger incumbency advantage and thus higher incumbency re-election rates.

The correlation of senator and voter ideology is significantly affected the size of the 
costs of adjustment and the the standard deviation in the positions of challengers, $\sigma_{x_{C}}$. To separate the standard deviation in the positions of challengers from the size of the costs of adjustment for incumbents, I include as a moment the correlation of senator and voter ideology for first term senators only. Holding adjustment costs constant, an increase in $\sigma_{x_{C}}$ will result in a lower correlation between the positions of senators and the median voter. This will be stronger for more junior senators, who do not have a long period of time to adjust their positions.

Finally, the standard deviation of challenger adjustment costs, $\sigma_{C}$ is identified by matching re-election rate of freshman senators. Freshman re-election rates provide identification of $\sigma_{C}$ because increases (decreases) in $\sigma_{C}$ decrease (increase) the correlation between the ideology of the median voter and the winning challenger's ideology. Because adjustment costs prevent freshman senators from moving far from the positions they had as challengers, the position they first campaigned on will directly impact their chances of re-election. A larger (smaller) $\sigma_{C}$ will result in lower (higher) re-election rates for freshman senators.

\section{RESULTS OF STRUCTURAL ESTIMATION}

The structural model is estimated estimated using ADA data from 1947-2006. Table 7 presents the results of estimation, reporting the parameters of the cost function (with standard errors in parentheses), the values of the moments, and the minimum statistic. I estimate a baseline case with no adjustment costs as well as models with quadratic, linear, and fixed costs to adjustment and a combination model. The combination model combines the quadratic and fixed costs of adjustment. Such a model allows for both the role of uncertainty (as in Enelow \& Munger (1993)) and character (as in Kartik \& McAfee (2007)).

Using the minimum statistic as the criteria, the model with both quadratic and fixed costs to adjusting position does the best at capturing the relevant moments. It is able to come very close to all four moments, and, in particular, does a much better job than the fixed cost model on matching the small number of large moves found in the data. The model with no costs of adjustment is clearly rejected by the data, with simulations showing 


\section{Table 7: Results of Structural Estimation}

\begin{tabular}{|c|c|c|c|c|c|c|}
\hline Model & No Cost & Linear & Quadratic & Fixed Cost & Fixed and Quad & Data \\
\hline \multicolumn{7}{|l|}{ Parameters } \\
\hline \multirow[t]{2}{*}{$\gamma$} & 0.000 & 0.000 & 2.040 & 0.000 & 0.983 & - \\
\hline & - & - & $(1.700)$ & - & $(0.119)$ & - \\
\hline \multirow[t]{2}{*}{$\kappa$} & 0.000 & 12.358 & 0.000 & 0.000 & 0.000 & - \\
\hline & - & $(0.045)$ & - & - & - & - \\
\hline \multirow[t]{2}{*}{$\mathrm{F}$} & 0.000 & 0.000 & 0.000 & 360.453 & 73.896 & - \\
\hline & - & - & & $(97.392)$ & $(34.716)$ & - \\
\hline \multicolumn{7}{|l|}{ Moments } \\
\hline Frac Jumps & 0.173 & 0.015 & 0.000 & 0.048 & 0.003 & 0.025 \\
\hline Serial Correlation & 0.340 & 0.217 & 0.333 & 0.054 & 0.237 & 0.263 \\
\hline Re-elect Rate & 0.832 & 0.836 & 0.830 & 0.820 & 0.846 & 0.843 \\
\hline Corr Ideo & 1.000 & 0.560 & 0.551 & 0.366 & 0.548 & 0.551 \\
\hline Corr Win/Dist & - & -0.033 & -0.015 & -0.006 & -0.024 & -0.119 \\
\hline Corr Ideo, Freshman & 1.000 & 0.497 & 0.413 & 0.358 & 0.451 & 0.462 \\
\hline Re-elect Rate, Freshman & 0.806 & 0.832 & 0.826 & 0.817 & 0.841 & 0.829 \\
\hline$£(\Theta)$ & 1054.983 & 22.232 & 58.238 & 78.292 & 20.593 & - \\
\hline
\end{tabular}

a Standard errors in parentheses below parameter estimates.

senators being much too responsive to changes in voter ideology.

As in the reduced form estimation, one finds large effects of changing position in the structural models. Any model with some costs of adjustment does much better at matching the relevant moments than does the model with no costs of adjustment. In the linear cost of adjustment model, a change of 6.63 ADA points (an average size change) lessens a candidate's chances of victory by the same probability as being about 9 points further away from the voter along the ideological spectrum (about the distance between John McCain and Strom Thurmond). This is very close to the quantitative significance found in the reduced form models.

Of the models with positive costs to adjustment, the worst fitting model is the model which posits only a fixed cost to adjusting position. In this model, any change in position, regardless of the size, is punished by voters and negatively affects a candidate's electoral prospects. Because of the large cost for any size change in position (any change incurs a cost equivalent to being about 18 points further way from the voters- more than the average distance between senators Joseph Lieberman and Ted Kennedy), the correlation between the ideologies of senators and voters is much lower than in the data.

Still, any model with a positive cost to adjusting one's position fits the data much better than the zero cost model. Senators move towards the voters, but, because of costs 
of adjustment, do not align themselves perfectly with the voters. Models where costs to changing position increase with the size of the change are the most consistent with the data. The best fitting model has both a variable cost and fixed costs component, suggesting signaling through persistent ideological stances is an important empirical phenomena. This result is consistent with the survey evidence of ?, who show voters dislike changes in position both because of the change itself and because of the increased uncertainty this provides regarding future positions of the candidate. Such preferences map well into the fixed and variable cost models I present above, and it is these models that best fit the data on electoral outcomes.

NEED TO PUT IN figures here with tenure profiles of distance and correlation of ideology. And discuss as note in referee response.

NEED TO PUT in electoral probabilities by size of change figure and discuss it.

\section{ROBUSTNESS}

\section{VII.I Close Elections}

One might suppose that electoral costs vary between states who strongly favor a particular party and those that are swing states. For example, it may be the class that flip-flopping is punished more in more partisan states since a candidates' biggest hurdle to re-election is the party primary and the median voter who is relevant is further from the center. To test this, I calculate the data moments used to estimate the models in the previous section, but do so only for elections where the winning candidate have between 45 and 55 percent of the vote share. I then estimate the model with quadratic and fixed costs using the methodology described above to find the parameters that best match the model moments to those from the data. The data and model moments, as well as minimum statistic are presented in Table ?? ${ }^{10}$ The model fits the data very well. What is important to note is that the serial correlation is much lower in close elections than in the sample of all elections. The correlation between voter and senator ideologies is also lower, as are incumbent re-election rates. The lower correlation between voter and senator ideology suggests that adjustment costs are actually higher in close elections, although this result could also be due to selection

\footnotetext{
${ }^{10}$ The estimate for the quadratic cost parameter is 0.461 and the fixed cost parameter is 200.97.
} 
effects. That is, candidates in close elections are in close elections because they happened to win office despite being positioned far from the median voter. However, two other moments highlight the importance of adjustment costs in these close elections. First, close elections have lower correlation between distance and the incumbent's re-election rate. The correlation may be lower because adjustment costs are relatively more important in these

elections. Second, the low serial correlation in position changes suggests that incumbents face large costs to changing position. And, in particular, that they face larger fixed costs to changing position. It is such fixed costs that result in a low serial correlation of position changes as candidates find it optimal to make larger position changes at one time rather than small position changes each term. This suggests that candidates in close elections will be more likely to be flip-floppers than to be wishy-washy candidates. Thus, there is strong evidence that candidates in close elections face even higher costs to position changes than those in other elections. This is consistent with the observation that close elections are those where a candidate's record is highlighted in the media and where each move receives more scrutiny.

PUT TABLE with close election moments here. first column is data moments, second is model moments and test stat.

\section{VII.II Voter Threshold}

It may be the case that voters are not well informed about the present and/or past positions of the candidate and thus can't accurately identify small changes in position. Or voters may simply not penalize small changes. Alternatively, there may be noise in the data that prevent the econometrician from accurately identifying small changes. Thus, it is of interest to consider a model where costs are incurred only for changes over a certain threshold. To determine what a reasonable threshold must be, I turn to the data, and in particular the correlation between the size of the incumbents change in position and his re-election probability. For all changes, this correlation is -0.07 . For changes smaller than five points on the ADA scale, the correlation is 0.03 . For those smaller than ten points it is -0.09 . And it is -0.15 for changes larger than ten points on the ADA scale. Thus, a threshold of five ADA points is a reasonable threshold, as a simple correlation suggests there may be little 
electoral cost to such small changes.

To see if such a model does a better in describing the data, I estimate the model with fixed and quadratic adjustment costs, but with no electoral cost incurred for changes smaller than the threshold of five ADA points. The model is estimated using the same moments and methodology as in Section VT. The minimum statistic found through estimation is XX.XXX. The model fits the data well, but not quite as well as the model where costs are incurred even on small changes.

\section{VII.III Measuring Distance from the Voter \\ VIII CONCLUSION}

The objective of this paper was to provide an understanding of the nature of "flipflopping" among United States senators. Using a large panel on the ideological positions of senators and various empirical approaches, the results suggest several important conclusions regarding the costs senators face when changing position.

First, I document electoral costs to changing position. These costs are economically significant, with changes in position resulting in electoral costs of similar magnitude to those seen from a divergence between the ideology of the voters and senators. Furthermore, I was able to clearly show that models which include adjustment costs fit the data much better than models with no costs to changing position. A model with both fixed and quadratic costs to adjusting position was found to fit the data best. That is, senators face costs to deviating from their past records that increase with the distance they move and also face a significant punishment for small deviations (measured by the fixed cost associated with changes). A model with fixed and quadratic adjustment costs support both the character models of Kartik \& McAfee (2007), Callander \& Wilkie (2007), and Callander (2008) (where fixed costs are important) and the models of uncertainty in future candidate positions such as Enelow \& Munger (1993).

Overall, the results provide more evidence against the stylized version of Downs' model and the convergence property of the Median Voter Theorem as a description of a representative democracy. Flip-flopping is indeed punished; any changes in position senators take is 
best done in small moves. While multiple models of electoral competition may be consistent with such a cost function, it is nonetheless important to understand such costs and their implications for electoral equilibrium such as non-convergence of candidate platforms. Understanding which model of adjustment costs fits the data best will help in the development of more realistic models of political competition.

A drawback of the model of electoral competition presented here is that it does not fully specify the dynamic models that result in the costs to adjusting position. The adjustment costs in this paper are reduced form approximations of complicated games of signaling and asymmetric information. Developing an estimable model that allows for these rich features is left as a worthwhile goal for future research. 


\section{References}

Alesina, Alberto. 1988. "Credibility and Policy Convergence in a Two-Party System with Rational Voters." The American Economic Review 78(4):796-805.

Alesina, Alberto \& Howard Rosenthal. 1989. "Partisan Cycles in Congressional Elections and the Macroeconomy." American Political Science Review 83:373-398.

Anderson, Sarah \& Philip Habel. 2008. "Revisiting Adjusted ADA Scores for the U.S. Congress, 1947-2007." Political Analysis 17:83-88.

Ansolabehere, Stephen \& James M. Snyder. 2004. "Using Term Limits to Estimate Incumbency Advantages When Officeholders Retire Strategically." Legislative Studies Quarterly 29(4):487-515.

Ansolabehere, Stephen, James M. Snyder Jr. \& Charles Stewart III. 2001. "Candidate Positioning in U.S. House Elections." American Journal of Political Science 45(1):136159.

Banks, Jeffrey S. 1990. "A Model of Electoral Competition With Incomplete Information." Journal of Economic Theory 50(2):309-325.

Bernhardt, M. Daniel \& Daniel E. Ingberman. 1985. "Candidate Reputations and the 'Incumbency Effect'." Journal of Public Economics 27(1):47-67.

Bronars, Stephen G. \& John R. Lott Jr. 1997. "Do Campaign Donations Alter How a Politician Votes? Or, Do Donors Support Candidates Who Value the Same Things That They Do?" Journal of Law and Economics 40(2):317-350.

Callander, Steven. 2008. "Political Motivations." Review of Economic Studies 75(3):671697.

Callander, Steven \& Simon Wilkie. 2007. "Lies, Damned Lies, and Political Campaigns." Games and Economic Behavior 60(2):262-286.

Cooper, Russell W. \& John C. Haltiwanger. 2006. "On the Nature of Capital Adjustment Costs." Review of Economic Studies 73:611-633. 
Dawes, Roy A. \& A. Hunter Bacot. 1998. "Electoral Career Patterns and Incumbency Advantage in the U. S. House of Representatives." Legislative Studies Quarterly 23(4):575583.

DeBacker, Jason M. 2011. "The Price of Pork: The Seniority Trap in the U.S. House." Journal of Public Economics 95(1-2):63-78.

Downs, Anthony. 1957. An Economic Theory of Democracy. New York: Harper.

Enelow, James M. \& Melvin J. Hinich. 1981. "A New Approach to Voter Uncertainty in the Downsian Spatial Model." American Journal of Political Science 25(3):483-493.

Enelow, James M. \& Michael C. Munger. 1993. "The Elements of Candidate Reputation: The Effect of Record and Credibility on Optimal Spatial Location." Public Choice 99:757-772.

Erikson, Robert S. 1990. "Economic Conditions and the Congressional Vote: A Review of the Macrolevel Evidence." American Journal of Political Science 34:373-399.

Glazer, Amihai \& Marc Robbins. 1993. "Congressional Responsiveness to Constituency Change." American Journal of Political Science 29:259-273.

Goffe, William L., Gary D. Ferrier \& John Rogers. 1994. "Global Optimization of Statistical Functions with Simulated Annealing." Journal of Econometrics 60(1-2):65-99.

Gourieroux, C., A. Monfort \& E. Renault. 1993. "Indirect Inference." Journal of Applied Econometrics 8(Supplement: Special Issue on Econometric Inference Using Simulation Techniques):S85-S118.

Gowrisankaran, Gautam, Matthew F. Mitchell \& Andrea Moro. 2008. "Electoral Design and Voter Welfare From the US Senate: Evidence from a Dynamic Selection Model." Review of Economic Dynamics 11(1):1-17.

Groseclose, Timothy, Steven D. Levitt \& James M. Snyder. 1999. "Comparing Interest Group Scores across Time and Chambers: Adjusted ADA Scores for the U S Congress." American Political Science Review 93(1):33-50. 
Ingberman, Daniel E. 1989. "Reputational Dynamics in Spatial Competition." Mathematical and Computer Modelling 12(4-5):479-496.

Kartik, Navin \& R. Preston McAfee. 2007. "Signaling Character in an Electoral Competition." American Journal of Political Science 97(3):852-870.

Levitt, Steven D. 1996. "How Do Senators Vote? Disentangling the Role of Voter Preferences, Party Affiliation, and Senator Ideology." American Economic Review 86(3):425441.

McFadden, Daniel. 1989. "A Method of Simulated Moments for Estimation of Discrete Response Models Without Numerical Integration.” Econometrica 57(5):995-1026.

Poole, Keith \& Howard Rosenthal. 1997. Congress: A Political-Economic History of Roll Call Voting. New York: Oxford University Press.

Poole, Keith T. 2003. "Changing Minds? Not in Congress!" Working Paper, Dept. of Political Science, Univ. of Houston .

Poole, Keith T. \& Howard Rosenthal. 1991. "Patterns of Congressional Voting." American Journal of Political Science 35:228-278.

Rust, John. 1987. "Optimal Replacement of GMC Bus Engines: An Empirical Model of Harold Zurcher." Econometrica 55(5):99-1033.

Somer-Topcu, Zeynep. 2009. "Timely Decisions: The Effects of Past National Elections on Party Policy Change." Journal of Politics 71(1):238-248.

Stewart III, Charles \& Jonathan Woon. 2006. "Congressional Membership Data, 80th to 109th Congresses, 1947-2006: Senate.".

Tauchen, George. 1986. "Finite State Markov-Chain Approximation to Univariate and Vector Autoregressions." Economics Letters 20:177-181.

Tufte, Edward R. 1975. "Determinants of the Outcomes of Midterm Congressional Elections." American Political Science Review 69:812-826. 